\title{
COMPOSTAGEM DE RESÍDUOS ORGÂNICOS: EFICIÊNCIA DO PROCESSO E
} QUALIDADE DO COMPOSTO

\author{
Alexandre Couto Rodrigues $^{1}$, Jacson Rodrigues França ${ }^{2}$, Rafael Borth da Silveira ${ }^{3}$, \\ Rodrigo Ferreira da Silva ${ }^{1}$, Clovis Orlando Da Ros ${ }^{1}$, Pedro Daniel da Cunha \\ Kemerich $^{4}$ \\ 1 Professor do Departamento de Ciências Agronômicas e Ambientais, Universidade \\ Federal de Santa Maria (UFSM), campus de Frederico Westphalen, Brasil. \\ (coutoalexandre@yahoo.com.br) \\ 2 Mestrando no Programa de Pós-Graduação em Engenharia Ambiental, UFSM, \\ campus de Santa Maria, Brasil. \\ 3 Engenheiro Ambiental e Sanitarista. Prefeitura municipal de Derrubadas, Brasil. \\ 4 Professor da Universidade Federal do Pampa (UNIPAMPA), campus de Caçapava \\ do Sul. Brasil.
}

\section{Recebido em: 08/09/2015 - Aprovado em: 14/11/2015 - Publicado em: 01/12/2015 DOI: http://dx.doi.org/10.18677/Enciclopedia_Biosfera_2015_116}

\begin{abstract}
RESUMO
A compostagem é uma técnica que possibilita a utilização adequada de resíduos orgânicos domiciliares, agropecuários e de agroindústrias, minimizando a contaminação ambiental. Com o objetivo de avaliar o processo de compostagem e a qualidade do composto foi conduzido um estudo com resíduos orgânicos de origem domiciliar, agropecuário e de agroindústria na Universidade Federal de Santa Maria. Os tratamentos foram cinco compostos orgânicos provenientes da compostagem de diferentes resíduos orgânicos. Foram utilizados resíduos orgânicos de baixa relação carbono/nitrogênio $(\mathrm{C} / \mathrm{N})$ (cama de frango, resíduo de restaurante universitário, resíduo orgânico de origem domiciliar, lodo do processo de flotação de frigorífico de aves e dejetos sólidos de bovinos), combinados com resíduos de alta relação $\mathrm{C} / \mathrm{N}$ (serragem, bagaço de cana-de-açúcar, palha de milho e de soja), arranjados em pilhas de camadas intercaladas de 5 a $10 \mathrm{~cm}$ do resíduo de baixa relação $\mathrm{C} / \mathrm{N}$ e de 15 a $20 \mathrm{~cm}$ de resíduo de alta relação $\mathrm{C} / \mathrm{N}$. As unidades experimentais foram compostas de três pilhas de compostagem por tratamento, construídas no formato cônico, com diâmetro médio de $1,2 \mathrm{~m}$ e 1,1 $\mathrm{m}$ de altura. $\mathrm{O}$ resíduo orgânico de restaurante universitário com serragem apresentou características próximas a ideal para possibilitar a recomendação do composto como substrato ou como fertilizante orgânico. Nos demais resíduos orgânicos é preciso adequar à proporção de serragem, palha de milho ou de soja nas pilhas de compostagem para reduzir o tempo de decomposição e a relação $\mathrm{C} / \mathrm{N}$, sendo que estes não apresentaram adequada disponibilidade de macro e micronutrientes no produto final da decomposição.
\end{abstract}

PALAVRAS-CHAVE: resíduos de agroindústria, resíduos agropecuários, resíduos domiciliares. 


\title{
COMPOSTING ORGANIC WASTE: THE PROCESS EFFICIENCY AND QUALITY OF COMPOUND
}

\begin{abstract}
Composting is a technique which enables proper use of household organic wastes, agricultural and agroindustrial minimizing environmental contamination. In order to evaluate the composting process and the quality of the compound was conducted a study of organic home residues, agricultural and agribusiness at Federal University of Santa Maria. The treatments were five organic compounds from different composting organic waste. Organic waste low ratio caborno/nitrogen $(\mathrm{C} / \mathrm{N})$ were used (poultry litter, the university restaurant waste, organic waste from household origin, sludge refrigerator flotation process poultry and solid cattle manure) combined with waste high $\mathrm{C} / \mathrm{N}$ ratio (sawdust, sugarcane bagasse, corn stover and soybean) arranged in stacks of interleaved layers of 5 to $10 \mathrm{~cm}$ from lower C/N residue and 15 to $20 \mathrm{~cm}$ high $\mathrm{C} / \mathrm{N}$ ratio residue. The experimental units were composed of three piles of compost per treatment, built in conical shape with an average diameter of $1.2 \mathrm{~m}$ and $1.1 \mathrm{~m}$ high. The organic residue of university restaurant with sawdust showed characteristics close to ideal to enable the recommendation of the compound as a substrate or as organic fertilizer. In other organic waste it is necessary to adjust the proportion of sawdust, corn straw or soybean in compost heaps to reduce the decomposition time and $\mathrm{C} / \mathrm{N}$ ratio, and they did not show adequate availability of macro and micronutrients in the final product of decomposition.
\end{abstract}

KEYWORDS: agribusiness waste, agricultural waste, household waste.

\section{INTRODUÇÃO}

A quantidade de resíduos orgânicos gerados nas últimas três décadas tem aumentado substancialmente o potencial de poluição ambiental (KEFALAS et al., 2011). Os resíduos orgânicos podem constituir uma fonte de poluição do solo, recursos hídricos e um meio de proliferação de insetos quando dispostos de forma inadequada no meio ambiente. No Brasil é baixa a proporção de resíduos que efetivamente são reciclados, sendo a maioria encaminhada para aterros sanitários, em lixões ou descartados ao ar livre. Desse modo, surgiram legislações que almejam a gestão ordenada desses resíduos, tais como a Lei Federal $\mathrm{n}^{0}$ 12.305/2010 que estipula a Política Nacional dos Resíduos Sólidos, que visa uma destinação e disposição final ambientalmente adequada a esses resíduos (BRASIL, 2010).

O aproveitamento dos resíduos orgânicos pode ser realizado por meio de um processamento, denominado compostagem, em pequena, média e grande escala. É uma alternativa para transformação dos resíduos sólidos orgânicos através da biodegradação por microrganismos (PEREIRA-NETO, 2007).

$O$ processo de compostagem também tem como definição uma decomposição controlada, exotérmica e bioxidativa de materiais de origem orgânica por microrganismos autóctones, num ambiente úmido, aquecido e aeróbio, com produção de dióxido de carbono, água, minerais, gerando uma matéria orgânica estabilizada, definida como composto ou húmus (PAULA et al., 2010), podendo ser utilizado como adubo orgânico, fonte de nitrogênio, fósforo, potássio, cálcio, magnésio, ferro, zinco, cobre, manganês e boro para as plantas (PAIXÃO et al., 2012), além de fornecimento de matéria orgânica, visando melhorar as propriedades químicas, físicas e biológicas do solo (RODRIGUES et al., 2014; 2015). 
A compostagem é uma técnica simples e de baixo custo, provavelmente, o mais antigo sistema de tratamento biológico utilizado pelo homem, tendo sido utilizado pelas antigas civilizações como um método natural de reciclagem dos nutrientes, comumente presentes, nos resíduos resultantes de suas atividades diárias (KIEHL, 2002; PEREIRA-NETO, 2007; MANO et al., 2010).

A reciclagem dos resíduos orgânicos é processada pela ação dos microrganismos presentes nos mesmos, os quais são responsáveis pela decomposição e/ou estabilização biológica da matéria orgânica, para transformá-la em compostos e húmus (MANO et al., 2010). As enzimas produzidas pelos microrganismos são responsáveis por transformar as formas complexas de carboidratos em formas simples, as quais são utilizadas como fonte de energia e carbono pelas bactérias, como acontece com a enzima celulase que degrada a celulose que é de difícil degradação (CAMPBELL, 1999).

As bactérias são microrganismos responsáveis pela quebra inicial de moléculas orgânicas de fácil degradação, como os açúcares, amidos e proteínas, resultando em formação de novos compostos e liberação de calor. Segundo KIEHL (2002), na compostagem encontram-se basicamente três tipos de bactérias: as criófilas, as mesófilas (maior número) e as termófilas, que atuam em temperaturas em torno de 13,25 e acima de $40^{\circ} \mathrm{C}$, respectivamente. Os fungos têm a função de degradar compostos carbonáceos e substâncias não decompostas por bactérias e fungos, sendo que estes microrganismos se reproduzem em ambientes de baixa umidade e altas temperaturas (PEREIRA-NETO, 2007). Normalmente, quatro a seis dias após a montagem da pilha de compostagem inicia-se o processo de decomposição por fungos (KIEHL, 2002).

A compostagem é influenciada por fatores que afetam a atividade microbiológica e a qualidade final dos compostos, como umidade, oxigenação, temperatura, granulometria do material, concentração de nutrientes e relação $\mathrm{C} / \mathrm{N}$ (PEREIRA-NETO, 2007). Segundo RUSSO (2003), os fatores que afetam o processo são os que determinam a existência de uma população diversificada de microrganismos necessários para completar a degradação, pois o oxigênio supre a demanda biológica, a temperatura influencia na velocidade das reações bioquímicas e a umidade processa as atividades metabólicas.

Com base nestas informações, o presente estudo tem o objetivo de avaliar a influência de resíduos orgânicos de origem domiciliar, agropecuário e de agroindústria na eficiência do processo de compostagem e na qualidade final do composto produzido.

\section{MATERIAL E MÉTODOS}

O estudo foi realizado na Universidade Federal de Santa Maria, campus de Frederico Westphalen, no período de março a setembro de 2012. O clima da região é subtropical úmido com verão quente, tipo $\mathrm{Cfa}$, com máximas maiores ou iguais $22^{\circ} \mathrm{C}$ e mínimas dos meses mais frios entre -3 a $18^{\circ} \mathrm{C}$ e com precipitação média anual entre 1.900 e $2.200 \mathrm{~mm}$ (ALVARES et al., 2013).

$O$ delineamento experimental foi 0 inteiramente casualizado com três repetições. A unidade experimental foi composta de uma pilha de compostagem construídas no formato cônico, com diâmetro médio de 1,2 $\mathrm{m}$ e 1,1 $\mathrm{m}$ de altura. Os tratamentos foram cinco combinações de resíduos orgânicos, constituídos de resíduos de baixa e alta relação carbono/nitrogênio $(\mathrm{C} / \mathrm{N})$. As denominações dos tratamentos e dos resíduos orgânicos utilizados nas pilhas de compostagem estão especificadas na Tabela 1. 
As pilhas de compostagem foram montadas após o nivelamento e drenagem do terreno, com camadas de 5 a $10 \mathrm{~cm}$ do resíduo orgânico de baixa relação $\mathrm{C} / \mathrm{N}( \pm$ $30 \%$ do volume) e intercaladas com camadas de 15 a $20 \mathrm{~cm}$ de resíduo orgânico de alta relação $\mathrm{C} / \mathrm{N}( \pm 70 \%$ do volume), revolvidas e umedecidas a cada três dias até o final da fase termófila e posteriormente uma vez por semana até o final do processo. A temperatura foi monitorada com termômetro de álcool e o estágio de maturação conforme metodologia descrita em OLIVEIRA et al. (2005), considerando a cor referente a fase de decomposição, se o líquido ficar escuro como tinta preta e apresentar a maior parte das partículas em suspensão, o composto está maduro. Por outro lado, se o líquido apresentar cor de chá ou café fraco e a maior parte do material se depositar no fundo do copo, então o composto está cru. Se o líquido mostrar uma coloração escura sem ser preta e um pouco de material em suspensão, a compostagem não terminou e o composto está na fase de semi-cura, ou seja, imaturo. Na figura $1 \mathrm{~b}$ pode ser visualizado o resultado do teste de maturação de um dos compostos no final da fase de decomposição (cor preta).

TABELA 1 Denominação dos tratamentos e dos resíduos orgânicos utilizados para compor as pilhas de compostagem

\begin{tabular}{|c|c|c|}
\hline \multirow{2}{*}{ Tratamentos } & \multicolumn{2}{|c|}{ Composição das pilhas de compostagem } \\
\hline & $\begin{array}{c}\text { Resíduos orgânicos com baixa } \\
\text { relação } \mathrm{C} / \mathrm{N}\end{array}$ & $\begin{array}{l}\text { Resíduos orgânicos com } \\
\text { alta relação CN }\end{array}$ \\
\hline CFR & $\begin{array}{c}\text { Cama de frango (CFR), proveniente } \\
\text { de aviário após seis lotes de } \\
\text { produção. }\end{array}$ & $\begin{array}{l}\text { Serragem + bagaço de } \\
\text { cana-de-açúcar }\end{array}$ \\
\hline $\mathrm{RRU}$ & $\begin{array}{l}\text { Resíduo orgânico de restaurante } \\
\text { universitário (RRU) do campus da } \\
\text { UFSM de Frederico Westphalen. }\end{array}$ & Serragem \\
\hline ROD & $\begin{array}{l}\text { Resíduo orgânico de origem } \\
\text { domiciliar (ROD), proveniente da } \\
\text { coleta seletiva de resíduos dos } \\
\text { municípios que compõem o } \\
\text { Consórcio Intermunicipal de } \\
\text { Gerenciamento dos Resíduos } \\
\text { Sólidos (CIGRES), com sede no } \\
\text { município de Seberi/RS. }\end{array}$ & $\begin{array}{c}\text { Serragem + palha de milho } \\
\text { e soja }\end{array}$ \\
\hline LPF & $\begin{array}{l}\text { Lodo do processo de flotação (LPF) } \\
\text { de resíduos de frigorífico de abate } \\
\text { de frangos }\end{array}$ & Serragem+ palha de milho \\
\hline DSB & $\begin{array}{l}\text { Dejetos sólidos de bovinos (DSB), } \\
\text { oriundos de propriedade de } \\
\text { produção de leite }\end{array}$ & Serragem \\
\hline Jac & $\begin{array}{l}\text { síduos orgânicos: CFR = } 14 \text { (KIEHL, 1985 } \\
\text { Il, 2011); DSB = } 18 \text { (KIEHL, 1985); Serrac } \\
\text { (KIEHL, 1985); palha de milho = } 112 \text { (INÁl }\end{array}$ & $\begin{array}{l}\text { U e ROD = } 13 \text { (INÁCIO, 2010) } \\
865 \text { (KIEHL, 1985); bagaço de } \\
\text { 2010); palha de soja = } 37 \text { a } 5 c\end{array}$ \\
\hline
\end{tabular}

Após a maturação do composto orgânico, obtido no processo de compostagem dos resíduos orgânicos, foram coletadas amostras em cada pilha de compostagem, em triplicatas, e acondicionadas em sacos de amostragem devidamente identificados, para análise de cada tratamento. Posteriormente, foram 
determinados $\mathrm{opH}$ em água, o carbono orgânico por oxidação com dicromato de potássio, os teores totais de nitrogênio por digestão úmida com ácido sulfúrico, os teores disponíveis de fósforo e potássio extraíveis pelo método Mehlich-1, os teores disponíveis de cálcio e magnésio com extração salina de $\mathrm{KCl}\left(1,0 \mathrm{~mol} . \mathrm{L}^{-1}\right)$, os teores disponíveis de enxofre extraível com a solução de fosfato de cálcio e os teores disponíveis de cobre e zinco extraíveis com $\mathrm{HCl}\left(0,1 \mathrm{~mol} . \mathrm{L}^{-1}\right)$, conforme metodologias descritas em TEDESCO et al. (1995).
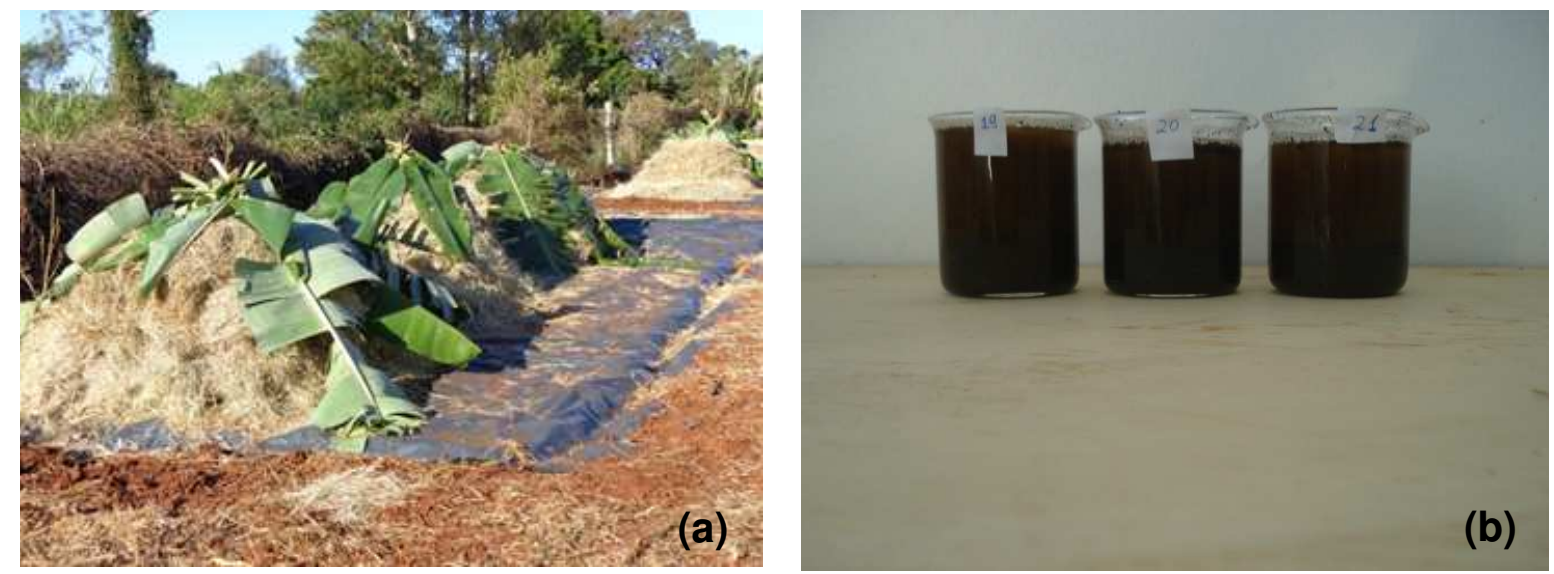

FIGURA 1. Formato das pilhas de compostagem (a) e teste de maturação realizado no composto (b).

Os dados das amostras dos compostos orgânicos foram submetidos à análise da variância e as médias de tratamentos comparadas pelo teste t de Student, a $5 \%$ de probabilidade de erro, pelo programa estatístico Sisvar 5.3 (FERREIRA, 2011).

\section{RESULTADOS E DISCUSSÃO}

A temperatura máxima observada nos compostos orgânicos durante o processo de compostagem foi de $30^{\circ} \mathrm{C}$ no composto de resíduos orgânicos domiciliares (ROD), $40^{\circ} \mathrm{C}$ na cama de frangos (CFR), $54^{\circ} \mathrm{C}$ no lodo do processo de flotação (LPF), $60^{\circ} \mathrm{C}$ nos dejetos sólidos bovinos (DSB) e $62^{\circ} \mathrm{C}$ no resíduo de restaurante universitário (RRU) (Figura 2).

Observa-se que apenas três dos cinco compostos orgânicos atingiram a temperatura entre 50 e $70^{\circ} \mathrm{C}$, considerada ideal para o processo de compostagem conforme os critérios e procedimentos, para uso agrícola de lodos de esgoto gerados em estações de tratamento de esgoto sanitário e seus produtos derivados (BRASIL, 2006). A elevada temperatura coincide com a acentuada atividade dos microrganismos no processo de decomposição e mineralização dos resíduos orgânicos (fase termófila), onde utilizam o carbono orgânico como fonte de energia e na formação da biomassa microbiana (PEREIRA, 2007). Segundo PEREIRA (2007), a ação dos microrganismos sobre os resíduos orgânicos aumenta com a elevação da temperatura até $65^{\circ} \mathrm{C}$ e que, acima deste valor, o calor limita as populações aptas, havendo um decréscimo da atividade biológica. Os autores ainda destacam que a elevação da temperatura é necessária para a eliminação de microrganismos patogênicos.

As menores temperaturas obtidas nas pilhas de compostagem com a inclusão de bagaço de cana-de-açúcar (CFR) podem ser atribuídas a maior granulometria do material que aumentou a dissipação do calor, que deve ter limitado a atividade microbiana, em comparação com os compostos que receberam somente serragem 
como componente de alta relação $\mathrm{C} / \mathrm{N}$ (RRU e DSB). Nestes dois resíduos provavelmente houve maior compactação e possibilitou a manutenção do calor gerado durante a decomposição, semelhante ao trabalho desenvolvido por BENITES et al. (2004), na qual a granulometria do material influenciou no tempo final e temperaturas da compostagem.

O baixo volume das pilhas de compostagem também pode ter contribuído para a menor concentração de calor, pois o aquecimento das pilhas de compostagem está relacionado às suas dimensões (RODRIGUES et al., 2014). Enquanto que as pilhas altas submetem as camadas inferiores aos efeitos da compactação, as pilhas baixas perdem calor mais facilmente ou nem aquecem 0 suficiente (PEREIRA-NETO, 2007). KIEHL (1985) recomenda pilhas de seção triangular, com largura entre 2,5 e 3,4 m, que são capazes de atingir altura entre 1,5 e 1,8 m. Provavelmente, o formato cônico de diâmetro e altura média de 1,2 e 1,1 m, respectivamente, das pilhas de compostagem do presente estudo tenham limitado a elevação da temperatura nos diferentes tratamentos em função da baixa atividade microbiana, pois segundo BUSNELLO et al. (2013), a falta de elevação da temperatura acarreta diminuição da atividade dos microrganismos, que pode influenciar diretamente no tempo de decomposição dos resíduos orgânicos.

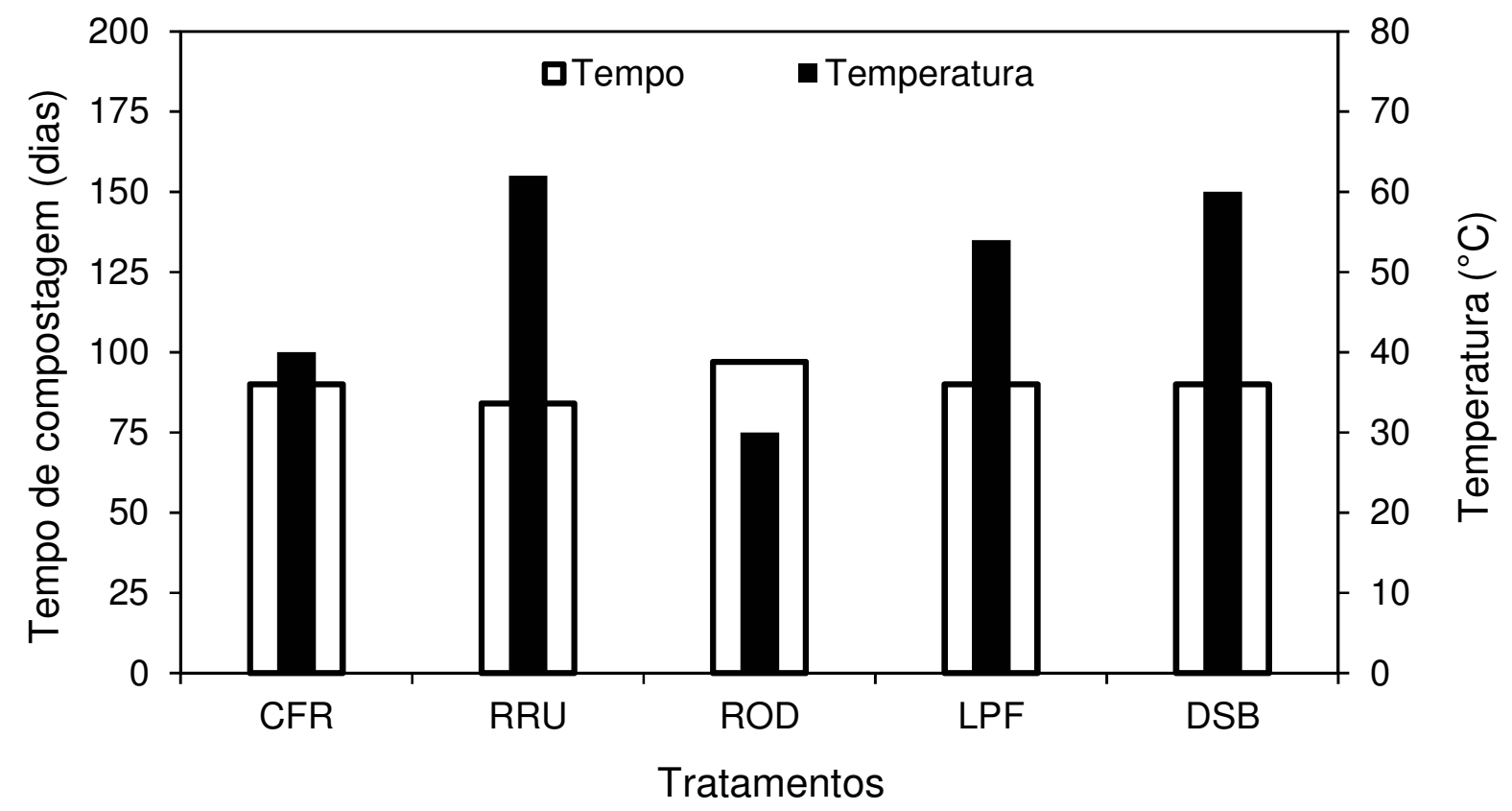

FIGURA 2 Tempo necessário para a compostagem e temperatura máxima das pilhas durante o processo de compostagem da cama de frango (CFR), resíduo orgânico de restaurante universitário (RRU), resíduo orgânico domiciliar (ROD), lodo de processo de flotação (LPF) e dejetos sólidos de bovinos (DSB).

O tempo de compostagem, avaliado com base na cor (coloração escura) foi de 84 dias no composto de RRU, 90 dias nos compostos com CFR, LPF e DSB e, de 97 dias, no ROD (Figura 2). Nestes compostos, o tempo do processo ficou próximo ou igual ao tempo ideal recomendado por OLIVEIRA et al. (2005), que é entre 60 e 110 dias. As diferenças entre os tratamentos provavelmente estão relacionadas à variação na relação $\mathrm{C} / \mathrm{N}$ e a quantidade de fibras dos resíduos orgânicos, o que influencia diretamente na decomposição (FARIAS et al., 2013). Os 
autores ressaltam que é necessária uma adequada combinação dos resíduos de alta relação $\mathrm{C} / \mathrm{N}$ (fonte de carbono) com os materiais de baixa relação $\mathrm{C} / \mathrm{N}$ (fonte de nitrogênio), como dejetos de animais ou resíduos de alimentos.

Observa-se que no final da compostagem a relação $\mathrm{C} / \mathrm{N}$ foi de 24 no composto com RRU, seguido de 29, 38, 52 e 61 nos compostos com LPF, CFR, DSB e ROD (Tabela 2). Considerando a elevada relação $\mathrm{C} / \mathrm{N}$ da serragem de madeira, a utilização da mesma nas pilhas de compostagem, na proporção de $70 \%$, extrapolou a relação $\mathrm{C} / \mathrm{N}$ do composto produzido com a adição deste material orgânico. Entretanto, essa relação ficou próxima da ideal no RRU, conforme recomendado pela Instrução Normativa do Ministério da Agricultura, Pecuária e Abastecimento (MAPA, 2009), que estabelece um valor máximo de 20. Isto demonstra a necessidade de diminuir a quantidade de serragem, bagaço de cana de açúcar e palha de milho na composição de todas as pilhas de compostagem, pois a elevada relação $\mathrm{C} / \mathrm{N}$ destes resíduos é um fator que dificulta a compostagem devido aos materiais recalcitrantes que constituem o tecido vegetal, como lignina e celulose. A relação $\mathrm{C} / \mathrm{N}$ satisfatória para a obtenção de alta eficiência nos processos de tratamento biológico dos resíduos sólidos orgânicos deve situar-se entre $30 \mathrm{e}$ 40:1 (PEREIRA-NETO, 2007).

TABELA 2 Teores totais de nitrogênio ( $N$-total), carbono orgânico (CO), relação $\mathrm{C} / \mathrm{N}$, capacidade de troca de cátions (CTC), saturação por bases (V), $\mathrm{pH}$ e teor de argila nos tratamentos provenientes da compostagem de resíduos orgânicos.

\begin{tabular}{|c|c|c|c|c|c|}
\hline \multirow{2}{*}{$\begin{array}{l}\text { Parâmetros } \\
\text { analisados }\end{array}$} & \multicolumn{5}{|c|}{ Tratamentos $^{(1)}$} \\
\hline & CFR & RRU & ROD & LPF & DSB \\
\hline N-total $\left(\mathrm{g} \cdot \mathrm{kg}^{-1}\right)$ & $12,2 c^{(2)}$ & $16,3 \mathrm{a}$ & $9,2 \mathrm{~d}$ & $13,2 b$ & $6,3 \mathrm{e}$ \\
\hline $\mathrm{CO}\left(\mathrm{g} \cdot \mathrm{kg}^{-1}\right)$ & $468,9 \mathrm{~b}$ & $399,7 \mathrm{c}$ & $561,2 \mathrm{a}$ & $386,8 \mathrm{c}$ & $327,5 \mathrm{c}$ \\
\hline Relação C/N & $38,0 \mathrm{c}$ & $24,2 d$ & $61,3 \mathrm{a}$ & $29,6 d$ & $52,1 \mathrm{~b}$ \\
\hline $\mathrm{CTC}_{\mathrm{pH} 7,0}\left(\mathrm{cmol}_{\mathrm{c}} \cdot \mathrm{dm}^{-3}\right)$ & $7,3 \mathrm{bc}$ & $8,2 a b$ & $5,6 \mathrm{bc}$ & $5,4 \mathrm{c}$ & $9,8 \mathrm{a}$ \\
\hline V (\%) & $79,9 \mathrm{~b}$ & $75,8 \mathrm{~b}$ & $74,5 \mathrm{~b}$ & $71,2 \mathrm{~b}$ & $90,3 \mathrm{a}$ \\
\hline $\mathrm{pH}_{\text {água (1:1) }}$ & $7,1 \mathrm{a}$ & $6,5 \mathrm{~b}$ & $6,8 a b$ & $6,9 a b$ & $6,6 \mathrm{~b}$ \\
\hline Argila $\left(\mathrm{g} \cdot \mathrm{dm}^{-3}\right)$ & $11,3 \mathrm{a}$ & $11,3 a$ & $7,3 \mathrm{~b}$ & $7,7 \mathrm{~b}$ & $7,3 \mathrm{~b}$ \\
\hline
\end{tabular}

$\mathrm{O}$ pH foi o parâmetro cujo valores foram superiores ao mínimo preconizado pela Instrução Normativa $\left(n^{\circ} 25\right)$ do MAPA (2009), que determina o valor igual ou superior a 6,0 (Tabela 2). BUSNELLO et al. (2013) destacam que no final do processo de compostagem o $\mathrm{pH}$ tende a ficar na faixa alcalina, entre 7,5 a 9,0.

Os valores adequados de $\mathrm{pH}$ podem estar relacionados a estabilização dos compostos com relação $\mathrm{C} / \mathrm{N}$ mais baixa presente nas pilhas de compostagem, sendo pouco influenciado na composição de resíduos de alta relação $\mathrm{C} / \mathrm{N}$ com a serragem, o bagaço de cana de açúcar e/ou a palha de milho, não sendo completamente decompostos. A atividade dos microrganismos na decomposição ENCICLOPÉDIA BIOSFERA, Centro Científico Conhecer - Goiânia, v.11 n.22; p. 765 2015 
dos resíduos de baixa relação $\mathrm{C} / \mathrm{N}$ provavelmente possibilitou a elevação do $\mathrm{pH}$ a valores próximos a neutralidade, pois conforme PEREIRA-NETO (2007) a faixa ótima de pH está entre 6,0 e 7,5 para a maioria das bactérias e entre 5,5 e 8,0 para os fungos.

A quantidade de nitrogênio total dos compostos variou de 6,3 a $16,3 \mathrm{~g} \cdot \mathrm{kg}^{-1}$ (Tabela 2), acima do limite de $5,0 \mathrm{~g} \cdot \mathrm{kg}^{-1}$ que é estabelecido pela normativa do MAPA (2009). Observa-se que mesmo com teores adequados de nitrogênio, a relação $\mathrm{C} / \mathrm{N}$ foi superior a 20 , indicando que é necessário diminuir a quantidade de resíduos de alta relação $\mathrm{C} / \mathrm{N}$ nas pilhas de compostagem, principalmente com o uso de ROD e DSB.

Os teores disponíveis de macro e micronutrientes mostram variação significativa entre os compostos orgânicos gerados pela compostagem dos resíduos orgânicos (Tabela 3). Conforme interpretação dos valores de referência para fósforo e potássio da CQFS (Comissão de Química e Fertilidade do Solo)-RS/SC (2004), extraído pelo método Mehlich-1, todos os compostos apresentaram valores acima do nível crítico para o crescimento das plantas, indicando que estes compostos apresentam potencial de fornecimento destes nutrientes quando utilizados com adubo orgânico ou como substrato para produção de mudas de hortaliças ou espécies florestais.

Os valores de enxofre nos compostos variaram de 6,3 a $32,3 \mathrm{mg}_{\mathrm{dm}} \mathrm{dm}^{-3}$ (Tabela 3), enquadrando-se dentro da classe "alta" conforme a CQFS-RS/SC (2004). MALAVOLTA et al. (2002) destacaram que esse elemento faz parte de algumas vitaminas e coenzimas que atuam no metabolismo celular das plantas, o que através da decomposição dos resíduos orgânicos ocorre a sua liberação e posterior concentração no material decomposto.

Observa-se que o composto com DSB apresentou os maiores valores nos teores de cálcio e magnésio (Tabela 3 ). Tomando como base, respectivamente, os valores de 4,0 e 1,0 cmolc. $\mathrm{dm}^{-3}$ de cálcio e magnésio, como teores adequados no solo (classe "alta") (CQFS-RS/SC, 2004), somente os compostos de DSB e de RRU apresentarem valores dentro desta classe. Isto indica que estes dois compostos podem ser utilizados como substrato ou como fertilizante orgânico com o objetivo de fornecimento de cálcio e magnésio, além de fósforo e potássio para as plantas, desde que não apresentam teores elevados de metais que possa comprometer a qualidade do solo e o crescimento das plantas.

Analisando os teores extraíveis de micronutrientes nota-se que os valores variaram significativamente entre os compostos, com menores valores de cobre, zinco nos compostos de ROD e LPF e maiores nos compostos de CFR, RRU e DSB (Tabela 3). Tomando como referência os teores da classe "alta" (CQFS-RS/SC, 2004), maiores que 0,40 e $0,50 \mathrm{mg} \cdot \mathrm{dm}^{-3}$ de cobre e zinco, respectivamente, observa-se que somente os compostos do CFR, RRU e DSB apresentaram teores acima do referencial para os dois micronutrientes. Ressalta-se que os teores de cobre e zinco acima do referencial podem ser considerados como parâmetro importante para a nutrição de plantas, mas deve-se destacar que elevados teores no composto podem causar fitotoxidade às plantas, quando utilizado como substrato para produção de mudas, e contaminação do solo e da água, no uso como fertilizante orgânico.

A resolução número 420, de 28 de dezembro de 2009, do Conselho Nacional do Meio Ambiente (CONAMA, 2009), dispõe de valores orientadores de qualidade de solo para prevenção de contaminação, que limita até $60 \mathrm{mg} \cdot \mathrm{kg}^{-1}$ de cobre e 300 $\mathrm{mg} \mathrm{kg}^{-1}$ de zinco, a fim de garantir a manutenção da principal função do solo que é 
de se servir como meio básico para a sustentação da vida e de habitat para pessoas, animais, plantas e outros organismos vivos. Deve-se ressaltar que os limites preconizados pela resolução são teores totais, diferentes dos teores disponíveis determinados no presente estudo. A inclusão de limites disponíveis também é um parâmetro que pode ser utilizado no monitoramento de contaminação de áreas com uso de adubo orgânico provenientes de resíduos urbanos ou agropecuários.

TABELA 3 Teores disponíveis de macronutrientes (fósforo, potássio, cálcio, magnésio e enxofre) e micronutrientes (cobre, zinco e boro) nos tratamentos provenientes da compostagem de resíduos orgânicos.

\begin{tabular}{|c|c|c|c|c|c|}
\hline \multirow{2}{*}{$\begin{array}{l}\text { Parâmetros } \\
\text { analisados }\end{array}$} & \multicolumn{5}{|c|}{ Tratamentos $^{(1)}$} \\
\hline & CFR & RRU & ROD & LPF & DSB \\
\hline & \multicolumn{5}{|c|}{---------------------- Macronutrientes ------------------------- } \\
\hline Fósforo (mg.dm³) & $76 \mathrm{~b}$ & $76,1 \mathrm{~b}$ & $47,9 \mathrm{c}$ & $76,1 \mathrm{~b}$ & $101,5 \mathrm{a}$ \\
\hline Potássio (mg.dm³) & $693,3 \mathrm{ab}$ & 368,2 c & $540,7 \mathrm{~b}$ & $156,4 d$ & 737,3 a \\
\hline Cálcio $\left(\mathrm{cmol}_{\mathrm{c} .} \mathrm{dm}^{-3}\right)$ & $2,7 \mathrm{~b}$ & $4,2 \mathrm{a}$ & $2,4 \mathrm{~b}$ & $2,9 \mathrm{~b}$ & $4,7 \mathrm{a}$ \\
\hline Magnésio $\left(\mathrm{cmol}_{\mathrm{c}} \cdot \mathrm{dm}^{-3}\right)$ & $1,4 \mathrm{~b}$ & $1,1 \mathrm{bc}$ & $0,8 \mathrm{bc}$ & $0,5 \mathrm{c}$ & $2,3 \mathrm{a}$ \\
\hline Enxofre $\left(\mathrm{mg} \cdot \mathrm{dm}^{-3}\right)$ & 32,3 a & $6,3 \mathrm{~b}$ & $7,4 \mathrm{~b}$ & $14,0 \mathrm{~b}$ & $\begin{array}{c}19,3 \\
a b\end{array}$ \\
\hline \multirow[t]{2}{*}{ Relação $\mathrm{Ca} / \mathrm{Mg}$} & $2,1 \mathrm{c}$ & $4,1 \mathrm{~b}$ & $3,7 \mathrm{~b}$ & $5,4 \mathrm{a}$ & $2,1 \mathrm{C}$ \\
\hline & \multicolumn{5}{|c|}{ 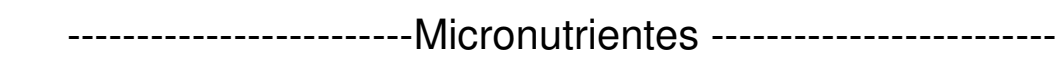 } \\
\hline Cobre $\left(\mathrm{mg} \cdot \mathrm{dm}^{-3}\right)$ & $1,0 \mathrm{~b}$ & $0,9 \mathrm{~b}$ & $0,4 \mathrm{c}$ & $0,4 \mathrm{c}$ & $2,2 \mathrm{a}$ \\
\hline Zinco $\left(\mathrm{mg} \cdot \mathrm{dm}^{-3}\right)$ & $14,2 b$ & $16,3 \mathrm{~b}$ & $3,5 d$ & $7,6 \mathrm{c}$ & $53,1 \mathrm{a}$ \\
\hline
\end{tabular}

(1) CFR: cama de frango; RRU: resíduos do restaurante universitário; ROD: resíduo orgânico domiciliar; LPF: lodo do processo de flotação; DSB: dejetos sólidos de bovinos. ${ }^{(2)}$ Médias seguidas pela mesma letra, na linha, não diferem entre si pelo teste de t de Student a $5 \%$ de probabilidade de erro.

$\mathrm{Na}$ análise conjunta de todos os parâmetros do processo de compostagem e de qualidade do composto destaca-se que somente o composto de origem de resíduos do restaurante universitário (RRU) apresentou quantidades disponíveis adequadas de macro e micronutrientes e também foi o único composto que apresentou relação $\mathrm{C} / \mathrm{N}$ próxima da ideal para ser recomendado como substrato ou como fertilizante orgânico. Nos demais compostos, é preciso adequar as quantidades de resíduos para reduzir a relação $\mathrm{C} / \mathrm{N}$ e aumentar a disponibilidade de nutrientes no produto final da decomposição. Com relação a cobre e zinco destacase que os valores estabelecidos pelo CONAMA (2009) são teores totais, diferentemente dos valores determinados no estudo (valores disponíveis). Independente disso, as doses e frequência de aplicação devem ser monitoradas para evitar possíveis contaminações com os metais no solo, principalmente de compostagem de lodo de estações de tratamento de esgoto, atividade industrial ou agroindústria, onde metais pesados, elementos ou compostos orgânicos sintéticos potencialmente tóxicos podem estar presente em alta quantidade. 


\section{CONCLUSÕES}

A combinação de resíduos orgânicos de restaurante universitário com serragem possibilita temperatura ideal e tempo adequado de compostagem, associado à relação $\mathrm{C} / \mathrm{N}$ próxima a ideal e adequada disponibilidade de macro e micronutrientes.

A compostagem de resíduos orgânicos domiciliares, lodo do processo de flotação e dejetos sólidos de bovinos não apresentam adequada disponibilidade de macro e micronutrientes no produto final da decomposição, necessitando-se de ajustes na proporção entre os resíduos de alta e baixa relação $\mathrm{C} / \mathrm{N}$.

\section{REFERÊNCIAS}

ALVARES, C. A.; STAPE, J. L.; SENTELHAS, P. C.; GONÇALVES, J. L. M.; SPAROVEK, G. Köppen's climate classification map for Brazil. Meteorologiesche Zeitschrift, v. 22, p. 711-728, 2013.

ABREU, P. G.; PAIVA, D. P.; ABREU, V. M. N.; COLDEBELLA, A.; CESTONARO, T. Casca de arroz e palhada de soja na compostagem de carcaças de frangos de corte. Acta Scientiarum. Animal Sciences, v. 33, p. 51-57, 2011.

BENITES, V. M.; BEZERRA, F.B.; MOUTA, R. O.; ASSIS, I. R.; SANTOS, R. C.; CONCEIÇÃO, M.; ANDRADE, A. G. Produção de adubos orgânicos a partir da compostagem dos resíduos da manutenção da área gramada do Aeroporto Internacional do Rio de Janeiro. Rio de Janeiro. Embrapa Solos, 2004, 21p. (Boletim de pesquisa e desenvolvimento, 50).

BERNARDI, F.H. Uso do processo de compostagem no aproveitamento de resíduos de incubatório e outros de origem agroindustrial. Cascavel: UNIOESTE, 2011. 78p.

BRASIL. Lei n. 12305, de 6 de agosto de 2010. Institui a Política Nacional de Resíduos Sólidos; altera a Lei no 9.605, de 12 de fevereiro de 1998 e dá outras providências. Diário Oficial da União, Brasília, DF, 7 ago. 2010. Disponível em: <http://www.planalto.gov.br/ccivil_03/_ato20072010/2010/lei/12305.htm>. Acesso em: 21 Jun. 2012.

BRASIL. Ministério do Meio Ambiente. Resolução CONAMA no 375 de 29 de agosto de 2006. Define critérios e procedimentos, para uso agrícola de lodos de esgoto gerados em estações de tratamento de esgoto sanitário e seus produtos derivados, e dá outras providências. Diário Oficial da União, Brasília, DF, n. 167, 30 de agosto de 2006, p. 141-146.

BUSNELLO, F. J.; KOLLING, D. F.; COSTA, R. D.; MOURA, L. C. pH e granulometria em compostagem de pequena escala com diferentes fontes de resíduos. In: VIII Congresso Brasileiro de Agroecologia. Anais.., 25 a 28/11 de 2013.

CAMPBELL, S. Manual de compostagem para hortas e jardins: como aproveitar bem o lixo orgânico doméstico. São Paulo: Nobel, 1999. 149p.

CONAMA. Conselho Nacional Do Meio Ambiente. Resolução № 420 de 28 de dezembro de 2009. Dispõe sobre critérios e valores orientadores de qualidade do ENCICLOPÉDIA BIOSFERA, Centro Científico Conhecer - Goiânia, v.11 n.22; p. 768 
solo quanto à presença de substâncias químicas e estabelece diretrizes para o gerenciamento ambiental de áreas contaminadas por essas substâncias em decorrência de atividades antrópicas. Diário Oficial da União, Brasília, DF, 31 de dezembro de 2009. Disponível em: <http://www.mma.gov.br/port/conama/res/re s09/res42009.pdf>.

CQFS-RS/SC - Comissão de Química e Fertilidade do Solo. Manual de adubação e de calagem para os Estados do Rio Grande do Sul e de Santa Catarina. 10.ed. Porto Alegre: SBCS/NRS, 2004. 400p.

FARIAS, W. M.; ANDRADE, L. A.; PEREIRA, E. D.; DIAS, B. O.; ALBUQUERQUE, M. B.; FRAGA, V. S. Propriedades físicas e químicas de substratos produzidos utilizando macrófitas aquáticas. Semina. Ciências Agrárias, v. 34, p. 3257-3269, 2013.

FERREIRA, D. F. Sisvar: a computer statistical analysis system. Ciência e Agrotecnologia, v. 35, p.1039-1042, 2011.

INÁCIO, C. T.; Compostagem de restos de alimentos com aparas de grama e esterco de animais: monitoramento do processo. Rio de Janeiro: Embrapa Solos, 2010 (Circular Técnica, 46).

KEFALAS, H. C.; SOUZA, S. A. D.; DENEKA, L. G. Resíduos orgânicos na zona costeira: a proposta da compostagem. In: SIMPÓSIO BRASILEIRO DE OCEANOGRAFIA, 2011, Anais... Santos: Oceanografia e Políticas Públicas, 2011.

KIEHL, E. J. Fertilizantes Orgânicos. São Paulo: Ceres, 1985.

KIEHL, E. J. Manual da Compostagem: maturação e qualidade do composto. São Paulo: USP, 2002.

MALAVOLTA, E.; GOMES, F. P.; ALCARDE, J. C. Adubos e Adubações. São Paulo: Nobel, 2002.

MANO, E.B.; PACHECO, E.B.A.V.; BONELLI, C.M.C. Meio Ambiente, Poluição e Reciclagem. 2ª̂nd. São Paulo: Blucher, 2010. 182 p.

MAPA. Ministério da Agricultura, Pecuária e Abastecimento. Secretaria de Defesa Agropecuária. Instrução Normativa no 25, de 23 de julho de 2009. Normas sobre as especificações e as garantias, as tolerâncias, o registro, a embalagem e a rotulagem dos fertilizantes orgânicos simples, mistos, compostos, organominerais e biofertilizantes destinados à agricultura. Disponível em: $<$ http://sistemasweb.agricultura.gov.br/sislegiaction/detalhaAto.do?method=consultar LegislacaoFederal>. Acesso em: 26 de Setembro de 2012.

OLIVEIRA, A. M. G.; AQUINO, A. M. de; CASTRO NETO, M. T. Compostagem caseira de lixo orgânico doméstico. Cruz das Almas: EMBRAPA, 2005. 
PAIXÃO R. M.; SILVA L. H. B. R.; TEIXEIRA T. M. Análise da Viabilidade da Compostagem de Poda de Árvore no Campus do Centro Universitário de Maringá CESUMAR. VI Mostra Interna de Trabalhos de Iniciação Científica. Anais.... ISBN 978-85-8084-4139, 23 a 26 de outubro de 2012. Disponível em: $<$ http://www.cesumar.br/prppge/pesquisa/mostras/vi_mostra/rebecca_manesco_paix ao_1.pdf>Acesso em: 08/10/2013.

PAULA, L. G. A.; CESAR, V. R.; OLIVEIRA, P. E. S.; Avaliação da Compostagem de Resíduos Orgânicos da Área Verde do Campus Marechal Deodoro. In: V CONGRESSO NORTE-NORDESTE DE PESQUISA E INOVAÇÃO, 2010, Maceió. Anais... UFA, 2010.

PEREIRA-NETO, J. T. Manual de Compostagem: Processo de baixo custo. $3^{a} E d$. Editora UFV, 2007. 81p.

PEREIRA-NETO, J. T. Gerenciamento do lixo urbano: Aspectos técnicos e operacionais. Editora UFV, 2007. 129p.

RODRIGUES, P.; RODRIGUES, A.C.; CAMARGO, M.; GRAEPIN, C.; NEUHAUS, F. Engenharias na Extensão Universitária: Conscientização Ambiental através da compostagem de resíduos orgânicos em Escola de Ensino Médio. Santa Maria: FACOS-UFSM, 2015. 167 p.

RODRIGUES, A.; CAMARGO, M.; RODRIGUES, P. Manual Didático de sobre Compostagem. Santa Maria: FACOS-UFSM, 2014. 28p.

RUSSO, M. A. T. Tratamento de resíduos sólidos. UFP, 2003 Disponível em: <http://homepage.ufp.pt/madinis/RSol/Web/T ARS.pdf.> Acesso em: 24 Jun. 2012.

TEDESCO, M. J.; VOLKWEIS, S. J.; BOHMEN, H. Análise de solo, plantas e outros materiais. Porto Alegre: UFRGS, 1995. (Boletim técnico de solos, 5). 